\title{
Hemodiyaliz Hastalarında Fistül Bakımı ve Mobil Sağlık Uygulamaları
}

\section{Fistula Care and Mobile Health Applications in}

\section{Hemodialysis Patients}

\author{
Cevriye ÖZDEMİ ${ }^{1}$, Merdiye ŞENDİR ${ }^{2}$
}

${ }^{l}$ Öğr. Görevlisi- Kayseri Üniversitesi, Incesu Sağllk Hizmetleri Meslek Yüksekokulu, Diyaliz Bölümü, Kayseri, Türkiye

${ }^{2}$ Prof. Dr.- Sağlık Bilimleri Üniversitesi, Hemşirelik Fakültesi, Hemşirelik Esasları AD, İstanbul, Türkiye

Geliş Tarihi / Received :

26 Nisan 2020

Kabul Tarihi / Accepted:

22 Eylül 2020

\section{İletişim yazarı}

Correspondence author

Cevriye ÖZDEMIR

E-posta: cevriyeozdemir@kayseri.edu.tr

\section{ORCID:}

Cevriye ÖZDEMIR

https://orcid.org/0000-0002-9401-0044

Merdiye ŞENDİR

https://orcid.org/0000-0002-8243-1669

\section{Özet}

Son yıllarda sağlık davranışlarına dikkat çekilmekte, bu alanda yapılan çalışma ve yaklaşımların arttı̆̆ görülmektedir. Bireyi sağlık davranışında değişikliğe teşvik etmek, yaşam biçimi değişikliği konusunda cesaretlendirmek ve bu konuda önerilen müdahalelerin günlük yaşama entegre edilmesi gibi desteklerinin olması gerekmektedir. Cep telefonları gibi bireylerin düzenli olarak taşıdığı mobil teknolojiler, bireylerin her an yanında olması nedeniyle cesaretlendirmek için etkili bir platform olabilmektedir. $\mathrm{Bu}$ nedenle son y1llarda tüm dünyada mobil teknolojiler yükselen bir akım haline gelmiştir. Günümüzde mobil teknolojiler çoğunlukla kronik hastalık yönetimi, yaşlı bakımı, bakıma muhtaç kişilerin ve yataklı tedavi sonrası hasta bireyin uzaktan izlemi gibi konularda sağlık personeli tarafindan kullanılmaktadır. Kronik hastalıklar içinde son dönem böbrek yetmezliği tanılı hastaların yaşamlarının her alanında kısıtlamaların olduğu bilinmektedir ve bu nedenle özellikle diyaliz makinasına bağımlı hastalar multidisipliner bir anlayışla ele alınmalıdır. Öz bakım davranışları ve bilgi seviyelerinin verilen eğitimler ve teşvik edici uygulamalar ile iyileştirilmesi gerekmektedir. Bu makalede, yazarlar tarafından yazılımı yapılmakta ve geliştirilmekte olan "Hemodiyaliz Hastalarında Mobil Sağlık Uygulaması ile Verilen Fistül Bakımı Eğitimi” bu yazılımla ilgili literatür bulunmamakta olup yazılım teknolojileri ile ilgili literatür incelemesine ilişkin bilgi paylaşımı amaçlanmıştır. Üzerinde çalıştığımız projemiz ile son dönem böbrek yetmezliği olan bireylerin kendi sağlık davranışları konusunda daha etkin ve kolay bir şekilde bilgi edineceği öngörülmektedir. Teknolojinin hızla geliştiği günümüzde bireylerin teknolojiyi kullanma becerisinin gelişmesi, etkin bir eğitim alması planlanmaktadır. Bu bağlamda, hemşirelerin eğitim rollerinde yeni teknolojik akımların kullanımının arttırılması ve hemşirelik uygulamalarının teknolojiye temellendirilmesi önerilmektedir. Yazılımını geliştirmekte olduğumuz uygulamamız ile hemşirelerin bakım ve eğitim hizmetlerinde yazılım benzeri bilişim teknolojilerinin kullanım sıklığını artırarak, hemşirelik uygulamalarının teknoloji ile donatılması hedeflenmektedir.

Anahtar Kelimeler: Hemşirelik; hasta eğitimi; mobil sağlık uygulamaları; arteriyovenöz fistül. 


\begin{abstract}
In recent years, attention has been drawn to health behaviors and it is seen that studies and approaches in this field have increased. They should have support such as encouraging the individual to change their health behavior, encouraging them to change their lifestyle, and integrating the proposed interventions into daily life. Mobile technologies carried by individuals such as mobile phones can be an effective platform to encourage individuals because they are always with them. For this reason, mobile technologies have become an increasing trend all over the world in recent years. Today, mobile technologies are mostly used by medical personnel in subjects such as chronic disease management, elderly care, caregivers, and remote monitoring of the sick individual after inpatient treatment. It is known that there are limitations in all areas of life of patients diagnosed with end-stage renal failure among chronic diseases, and therefore patients especially dependent on dialysis machines should be handled with a multidisciplinary approach. Self-care behaviors and knowledge levels need to be improved through training and encouraging practices. In this article, "Fistula Care Training Given with Mobile Health Application in Hemodialysis Patients", which is being developed and developed by the authors, is not available for this software, and it is aimed to share information about the literature review of software technologies. With the project we are working on, it is predicted that individuals with end-stage renal insufficiency will learn more effectively and easily about their health behavior. Today, when technology is rapidly developing, it is planned that individuals' ability to use technology will develop and receive an effective education. In this context, it is recommended to increase the use of new technological currents in nursing education roles and to base nursing practices on technology. It is aimed to equip nursing applications with technology by increasing the frequency of use of software-like information technologies in the care and education services of nurses with our application that we are developing software.
\end{abstract}

Keywords: Nursing; patient education; mobile health applications; arteriovenous fistula.

\section{GíRiș}

Son on y1lda akıllı telefonlar günlük yaşamımızın her alanında vazgeçilmez bir unsur olmuştur. Dijital 2019 raporuna göre dünya genelinde son bir yılda aktif cep telefonu kullanımının 100 milyon (2018 raporuna göre yüzde 2'nin üstünde) arttığı rapor edilmiştir (1). Uluslararası Veri Şirketi (Worldwide Quarterly Mobile Phone Tracker (IDC))'nin raporuna göre, dünya pazarında akıllı telefonların üretim ve tüketimi geçen yıla oranla \%39 büyümüştür (2). Bu rakamlar, yalnızca akıllı telefonlarm benimsenmesinin evrensel hale geldiğini değil, aynı zamanda pazarın akı1lı telefon alanında hızla ilerlediğini göstermektedir. Akıllı cep telefonları, bilgisayarlar gibi internete erişebilen ve çeşitli karmaşık uygulamaları çalıştıran güçlü cihazlar olarak küresel sağlık dünyasında çekici olmuş ve yaygınlaşmıştır.
Sağlığ1 korumada en önemli etkenlerden biri sağlıkla ilgili riskleri azaltmak ve bunu sağlamak için bireyleri sağlık enformasyonu konusunda bilinçlendirmek olduğu belirtilmektedir. Bunun ise ancak sağlık okuryazarlı̆̆ ile sağlanabileceği vurgulanmaktadır (3). Sağlık hizmetlerinde kullanılan bilgi ve iletişim teknolojisi (BİT) de tam bu aşamada devreye girerek sağlık profesyoneli ve hasta birey arasında yeni dönem iletişim ağı oluşturmaktadır $(4,5)$. Sağlık alanında, bütün sağlık profesyonelleri tarafından kabul gören görüşlerden biri de hastanın kendi tedavi ve bakım sürecine dâhil olmasıdır. $\mathrm{Bu}$ durum literatürde "hastayı güçlendirme" olarak tanımlanmaktadır. Hastayı güçlendirme, onun karar verme sürecine aktif olarak katılması, kabul edilen tedavi için sorumluluk alması ve kendi sağlık durumunu izlemesi şeklinde açıklanabilmektedir. Bunun yanı sıra, hastanın kendi hastalığı ya da durumu ile ilgili 
bilgi aramasını da içermektedir (5). Bu sağlık anlayışı, bireyin kendi sağlığı ile ilgili sorumluluk almasını, hastalıktan önce sağlıklı yaşamaya ve sağlı̆̆ını korumaya özen göstermesini beklemektir. $\mathrm{Bu}$ anlayış; bireylerin sağllk verilerini yanında taşıyabildiğ $i$, istediğ $i$ zaman tüm sağlık verilerine ulaşılabildiği ve bunların her zaman kontrol altında tutulduğu, hastaları kendi sağlıklarına ilişkin aktif kılan bir yaklaşımdır. $\mathrm{Bu}$ anlayış mobil sağlık uygulamalarının ön plana çıkmasına neden olmaktadır. Özellikle yaşam süresinin uzaması nedeniyle kronik hastalıkların artışı, sağlık hizmeti maliyetlerinin artışı, sağlığın kişiselleştirilmesi gibi nedenler mobil sağlığın gelişme nedenleri arasında gösterilebilir (6).

Günümüzde mobil uygulamalar, dünya çapında milyonlarca kullanıcı için günlük yaşamın ayrılmaz bir parçasıdır. Daha spesifik olarak, birden fazla çevrimiçi platform ve sanal topluluk, çeşitli kronik hastalıklar hakkında hızlı ve interaktif bir iletişim kurmak için giderek daha fazla kullanılmaktadır $(7,8)$. Mobil uygulamaların sağlık davranışlarında büyük ölçüde olumlu etkisinin olduğu gösterilmiştir (9). Bireyleri sağlik davranışlarında olumlu değişikliğe teşvik eden, özellikle kronik hastalıklara sahip bireylerin öz bakımlarında bireyi cesaretlendirmek, öz bakım girişimlerini günlük yaşamlarının bir parçası haline gelmesine olanak sağlamada desteklerin olması gerekmektedir. Her geçen gün kullanımı yaygınlaşan ve bireylerin düzenli olarak taşıdığı akıllı telefonlar, günlük yaşamın ayrılmaz parçası durumuna gelmiştir ve bu nedenle de akıllı telefonlar bireyleri sağlıklarını koruma, refahlarını artırma ve bu alanda cesaretlendirme konusunda etkili bir platform olarak görülmektedir. Bu platformlar incelendiğinde özellikle fiziksel aktivite konusunda tasarlanmış mobil uygulama sayısının fazlalığı dikkat çekmektedir.

Kronik hastalıklar tıbbi girişimler ile kesin tedavisi sağlanamayan, hastalığın seyrini iyileştirmek ve öz bakımda kişinin yetisini en üst düzeye çıarmak için multidisipliner izlem ve bakım gerektiren klinik tablolardır. Kronik hastalıkların görülme sıklığı ve yaygınlığı; bu grup hastalıkların ciddi bir halk sağlığını sorunu olduğunu ortaya koymaktadır. Kronik hastalıkların kısa ve uzun vadede komplikasyonları insanların üret- kenliğini ve yaşam kalitesini tehlikeye düşürmektedir (10). Kronik hastalıklar içinde en fazla makinaya bağımlı olan grup son dönem böbrek yetmezliği (SDBY) tanılı hastalardır ve bu hastalık yaşamın her alanında kısıtlamalara yol açmaktadır (11). Bu nedenle özellikle diyaliz makinasına bağımlı hastalar multidisipliner bir anlayışla ele alınmalıdır (12). Hemodiyaliz hastalarının arteriyovenöz fistül öz bakım davranışlarının düşük veya orta düzey olduğu, fistül bakımı hakkında bilgi gereksinimleri olduğu saptanmıştır $(13,14)$. Bu nedenle öz bakım davranışı ve bu konudaki bilgi seviyelerinin verilen eğitimler ve teşvik edici uygulamalar ile iyileştirilmesi gerekmektedir. Kabul edilen ve benimsenen yaşam biçimi, bireyin yaşam kalitesini belirlemektedir. Çünkü kişisel, sosyal ve fiziksel aktivitelerle geçirilen zaman, fiziksel ve zihinsel işleyiş yanında günlük yaşam aktivitelerine katılımı da etkiler. Yaşam biçimi, bir kişinin yaşamındaki tutumları, değerleri ve firsatları yansıtan tercihlerle ilişkilidir ve insan sağlığını etkileyen bir davranış modeli olarak tanımlanabilmektedir (15).

Sağlık alanına özel olarak tasarlanmış mobil uygulamalar ile bireylerin sağlık durumlarına ilişkin verilerin izlemini sağlanmaktadır. Mobil uygulamalar aynı zamanda sağlık davranışı değişikliğini teşvik etme ve kronik hastalık öz bakımı için destek sağlayabilmektedir. Ancak bu yararların sağlanabilmesi için de birçok koşulun etkili bir şekilde yönetilmesi gerekmektedir. Sağlık ekibinin hastanın semptomları, aktiviteleri ve fizyolojik parametreleri hakkında bilgilendirilmesi gerekmektedir; böylelikle bu durum sağlı hizmetinin daha etkili ve hızlı bir şekilde yapılmasına olanak sağlayabilecektir. Bu hizmetin mobil uygulamalar ile daha da güçleneceği düşünülmektedir. Bu makalede önemi vurgulanan mobil sağlık uygulamasının yazılım üretme süreci devam etmekte olup, aktif kullanıma sunulduğunda Türkiye'de bilişim hemşireliği konusunda hemşirelere teşvik edici bir rehber uygulama olacağ 1 düşünülmektedir.

\section{Mobil Sağlık}

Mobil sağlık ya da daha yaygın olarak M-Sağlik halk sağlığını ve klinik uygulamayı desteklemek için kablosuz iletişim cihazlarının kullanılmasıdır 
(16). Dünya genelinde sağlık hedeflerine ulaşmak için mobil ve kablosuz teknolojilerin kullanılması sağlık hizmeti sunumunun seyrini dünya çapında dönüştürme potansiyeline sahiptir. Mobil teknolojiler ve uygulamalardaki hizlı ilerlemeler, mobil sağlığın mevcut E-Sağlik hizmetlerine entegrasyonunun sağlanması ile sürekli büyümektedir. Uluslararası Telekomünikasyon Birliği (International Telecommunications Union) şu anda dünyada 5 milyara yakın cep telefonu aboneliği bulunduğunu ve dünya nüfusunun $\% 85$ 'inden fazlasının şu anda kablosuz sinyalle internet ağına bağlı olduğunu bildirmektedir (17).

Mobil teknolojilerin günümüzde yaygınlaşması, bireylerin sağl1k bilgilerine her zaman ulaşabileceği yeni bir paradigmaya giden yolu açmaya yardımcı olmaktadır. Taşınabilir ve giyilebilir teknolojiler, bireylerin fizyolojisi, psikolojisi ve davranışlarıyla ilgili verileri toplamak için giderek daha fazla kullanılmaktadır. Bu değerli bilgiler sağlık risklerini azaltmak, hastalık komplikasyonlarını optimize etmek, bireyleri öz bakım konusunda bilinçlendirmek, sağlık durum belirleyicilerini anlamak ya da hastalığa neden olan faktörlere yeni bakış açısı getirmek için kullanılabilmektedir.

Mobil sağlık teknolojileri, sağlık bakım hizmetini davranışsal değerler temelinde bireylere özel olarak uyarlamada eşsiz firsatlar sunmaktadır (18). M-Sağlık ayrıca teknolojinin anlık işlevselliği ve birçok seçeneği ile sürekli kullanımı göz önüne alındığında daha fazla hasta katılımını vaat etmektedir. M-Sağlık teknolojilerinin yaratıcı kullanımı ile sağlık hizmetlerinin maliyetini düşürme, sağlık araştırmalarını ve sonuçlarını geliştirme potansiyeline sahip olduğu belirtilmektedir. $\mathrm{Bu}$ teknolojiler hem bireysel hem de toplumsal düzeyde sürekli bir şekilde, sağlık durumu izleme, sağlık sorunlarını önleme veya azaltma bunun için uygun sağlık davranışlarına teşvik etme konusunda destekleyici olabilmektedir. Bunun yanı sıra kronik hastalık yönetimini ve öz bakımı destekleyebildiği, kullanıcının bilgisini artırabildiği, ev ziyaretlerinin sayısını azalttığı, kişiselleştirilmiş ve isteğe bağlı girişimler yapılabildiği belirtilmektedir (19-21).
Mobil sağlık uygulamaları işletim sistemleri tarafindan pazarlanır, Android ve iOS ise en sık kullanılan sistemlerdir. Her iki işletim sisteminin kalite başarısı tartışılmaz ve uygulamalar çevrimiçi mobil uygulama mağazaları (Apps) tarafindan sağlanmaktadır. Bu çevrimiçi mağazalar, uygulama geliştirici ve yazılımcılara her türlü uygulamayı satmak veya ücretsiz olarak sunmak için her zaman açıktır. 2010 yılı sonunda, dünya çapındaki bireylerin yaklaşı \%70'i 200 milyondan fazla M-Sağlık uygulaması indirdiği ve en az bir tane M-Sağlık uygulamasına erişmek istediğ belirtilmiştir (22).

Mobil sağlık uygulama pazarları hastalara, kliniklerde çalışanlara ve sağlık uzmanlarına yöneliktir. Bu uygulamalar çoğunlukla hastalık yönetimi, kendi kendine izleme ve hastalık kontrolünün yanı sıra diğer klinik ve eğitsel uygulamalar için de uygundur. Mobil uygulamalar çoğunlukla eğlence, bilgi ve günlük yaşam prosedürlerinin kolaylığına odaklanmakta olup; çok sayıda şirket, yazılım geliştirici ve özel girişimciler tarafından ilgi çekmektedir. Bunun yanı sıra sağlıkla ilgili uygulamaların ve cihazların geliştirilmesi BITT sektöründe en hızlı büyüyen alanı temsil etmektedir. Özellikle uzak bölgelere erişilebilirliği sağlarken hasta bakımını daha hassas, verimli ve uygun maliyetli hale getirerek küresel sağlik sistemleri için büyük firsatlar sunmaktadır (23).

Mobil sağlık pazarı hızla gelişmekte ve yeni mobil teknolojileri sağlık hizmeti için kullanılabilir hale getirmektedir (24). Semptomların izlenmesi, hekimle ortak karar verme ve kolayca erişilebilir eğitim yoluyla hastanın kendi sağlık bakımı konusunda güçlendirilmesi, M-Sağlık teknolojisini geleneksel bakımın ötesine taşıyan önemli özelliklerdir. Özellikle mobil uygulamaların kronik hastalık öz yönetimi ve bakımı konusundaki desteğinin komplikasyonları önlemede yararl1 etkilerinin olduğu bulunmuştur $(25,26)$.

Mobil uygulamalar tıbbi hataların azaltılması, zamanı etkin kullanma, klinikteki iş akışının düzenlenmesi, güven duygusunun artması ve maliyetlerin düşmesi gibi etkileri sonucu kaliteli sağlık hizmetine katkı sağlamaktadır. Mobil sağlık uygulamalarının uygun kullanımının hasta bireyin sağlık yönetiminde ve tedavi konusunda 
bilinçli kararlar almasına yardımcı olduğu belirtilmektedir $(27,28)$. Mobil sağ 1 ğın, bakım kalitesini artırma, hasta bireylerin refah seviyesini yükseltme ve sağlık hizmetinde verimliliği artırma konusunda klinik bakımın ayrılmaz bir parçası olma yolunda hızla ilerlediği görülmektedir (29).

\section{Arteriyovenöz Fistül ve Bakımı}

Ülkemizde en yaygın kronik hastalıklardan biri son dönem böbrek yetmezliği hastalığıdır ve bu taniy1 alan hastalarda renal replasman tedavileri uygulanmaktadır $(30,31)$. Renal replasman tedavilerini hemodiyaliz (HD), periton diyalizi (PD) ve böbrek transplantasyonu oluşturmaktadır. Türk Nefroloji Derneği'nin 2017 verilerine göre, ülkemizde HD uygulanma sıklığı \%76'dır (32). SDBY tanis1 olan bireylerin tedavisinde en s1k HD uygulanmakta olup, bu tedavi ile hastaların daha kaliteli ve uzun yaşayabilmeleri sağlanmaya çalışılmaktadır (33). Etkin bir HD tedavisi için arteriyovenöz fistül (AVF), arteriyovenöz greft (AVG), geçici veya kalıcı kateterler ile sağlanan vasküler erişim yolu gerekmektedir. Hemodiyaliz hastalarının tedavisinde vasküler erişim yollarından en ideal olanı arteriyovenöz fistüldür. Arteriyovenöz fistül, yüzeyel venin arteriyalize edilerek kanülasyonu kolay, komplikasyonu az olan diyaliz işlemi esnasında yeterli kan akımını sağlayacak bir damar yapısı oluşturulmasıdır. Tedavide vasküler erişim yollarının kullanılması hastanın yaşam süresi ve kalitesini doğrudan etkilemektedir. Bu nedenle SDBY olan bireylerde tedaviye uyum hayati önem taşımaktadır. Bireyin öz bakım davranışlarındaki yetersizlik, tedaviye uyumu bozarak, tedavinin etkinliğini azaltmakta ve maliyeti arttırmaktadır.

Hastaların AVF'lerine ilişkin bilgi, tutum ve bakım uygulamaları bu konuda bilgi ve uygulama eksikliğinden kaynaklanabilmektedir. Öz bakım davranışının gelişimi, hasta bireyin hastalık yönetimine aktif katılımını sağlar ve AVF'lerinin olas1 komplikasyonlarını erken saptanmasını sağlar (34). Ayrica hasta bireylerin kendi vasküler erişimleri ile ilgili komplikasyonları tanımlama olasıllı̆ı daha yüksektir $(34,35)$.

Bu kapsamda arteriyovenöz fistül bakım eğitim içeriği şu şekilde sıralanabilir;
- Hastanın yeni bir fistülü varsa o ekstremiteyi elevasyonda tutması söylenmelidir.

- Yeni bir fistül için o ekstremiteye yapılması gereken el egzersizlerini öğretmeli ve kola hafifçe uygulanan turnikenin fistülün olgunlaşmasına yardımcı olacağı anlatılmalıdır.

- Fistül anastomozu olan bölgedeki "thrill (titreşim)"'in hissedilmesi ve üfürümün dinlenmesi gerektiği öğretilmeli, "thrill” ve üfürüm karakterinde bir değişiklik fark edildiğinde acilen doktora başvurması gerektiği söylenmelidir.

- Hastanin hemodiyaliz seansina gelmeden önce fistüllü kolunu enfeksiyon riskini azaltmak için sabunlu 1 l1k su ile yıkaması ve kurulaması söylenmelidir.

- Fistül bölgesinde gelişebilecek olası enfeksiyon belirtileri (kızarıklık, kaşıntı, ısı artışı vb.) öğretilmelidir.

- Uyurken fistül olan kolun basınçtan korunmas1 ve o ekstremiteye kol saati, bilezik gibi takı aksesuarlarını takmaması gerektiği hastaya anlatılmalıdır. Kolu çepeçevre saran bandaj, sarg1 ve sık1 kıyafetler kullanmaması hakkında bilgi verilmelidir. Ayrıca, fistüle gelen kan akımını engelleyen davranışların fistül/greft kaybına neden olabileceği belirtilmelidir.

- Fistül olan koldan kesinlikle kan aldırmaması, herhangi bir tedavi yaptırmaması, kan basinc1 ölçtürmemesi anlatılmalıdır. Hatta olas1 komplikasyonlardan dolayı diğer kolunu daima koruması gerektiği konusunda farkındalığ 1 artırılmalıdır.

- Fistül olan kol ile ağır işler yapmaması ve ağırlık taşımaması, taşıyacağı ağırlığın 1 kg'1 aşmaması vurgulanmalıdır.

- Kesici-delici aletler kullanırken çok dikkatli olması ve kolunu her türlü travmadan koruması gerektiği anlatılmalıdır. Travmaya bağ 11 şiddetli kanama gelişebileceği ve bu durumda kanama üzerine bask1 yaparak en yakın hastaneye başvurması gerektiği söylenmelidir.

- Hipotansiyona neden olabilecek durumlardan (aşırı sıcak ortam, diyaliz seansında kuru ağırlığın altına inilmesi, iki hemodiyaliz seansı 
arasında fazla sıvı alınması nedeni ile hemodiyaliz seansında hastanın hemodinamisinin bozulması vb.) kaçınması anlatılmalı; bayılması, baş dönmesi veya düşme sonrası fistülün kontrol edilmesi gerektiği anlatılmalıdır. Ayrıca tansiyon düştüğünde;

- Hemen yere uzanıp ayaklarını yukarıya kaldırmas1,

○ Tansiyonunu ölçtürmesi,

○ Fistül sesinde bir azalma olup olmadığını kontrol etmesi,

- Tansiyonu yükselmiyorsa ve fistül sesinde bir azalma varsa hemşire veya doktoruna haber vermesi gerektiği konusunda bilgilendirilmelidir.

- Sigara, alkol gibi alışkanlıkları varsa bırakması konusunda gerekli danışmanlık ve ilgili yerlere başvurması konusunda bilgilendirilmelidir.

Yukarıda belirtilen öz bakım davranışları hasta bireylere bağlı bulundukları kurum ya da hastanelerde eğitim broşürü/kitapçığı ya da sözel olarak eğitimleri verilmektedir. Burada verilen konuları içeren hasta eğitimine mobil teknoloji entegresyonunun sunulan hizmeti daha etkin kılabileceği ve özbakım yönetiminde hastanın güçlendirilmesine katk1 sağlayabileceği öngörülmektedir.

\section{Hemodiyaliz Hastalarında Arteriyovenöz Fistül Bakımı İçin Mobil Uygulama Geliştirilmesi}

Hemşireler, sağlık işgücünün en büyük sağlık sağlayıcı grubunu oluşturmaktadır ve bu nedenle BİT uygulama süreci için önemli bir grubu temsil etmektedir. Tüm hemşirelik hizmetleri bir şekilde bilgi teknolojisinin gelişiminden etkilenmiştir (36). Hemşireler hastalarla en fazla etkileşime sahip olan sağlık profesyoneli olarak teknoloji ile daha fazla ilişki içerisindedirler. Bu nedenle, bakımın kalitesini artırmak için hemşirelerin BİT tasarımına katılmaları büyük önem arz etmektedir. Böylelikle gelişen teknolojinin yardımıyla hemşireler, daha fazla karar verme ve yetki alanına sahip olabileceklerdir.
Sağl1k sektöründe, bilgi teknolojisi ve sağlık profesyonelleri arasında iletişim ihtiyacını karşılamak amacıyla hemşire bilişim uzmanı pozisyonları oluşturulmuştur. Hemşire bilişim uzmanları, sağlık hizmeti sunum sürecinin ayrılmaz bir parçasıdır ve güvenli, kaliteli, hasta merkezli bakımı destekleyen sağlık hizmetlerinin seçimi, uygulanmas1 ve değerlendirilmesinde belirleyici bir faktördür (37). Amerikan Hemşireler Derneği (2008) Hemşirelik bilişimini "Hemşirelik uygulamasında veri, bilgi ve bilgiyi yönetmek ve iletmek için hemşirelik bilimi ile bilgisayar bilimini birleştiren bir uzmanlık alanı" olarak tanımlamıştır. Bilişim hemşireleri, hasta bakımında bilgi ile ilgili faaliyetleri gerçekleştirmek için verimli bir iş akışı sağlamak amacıyla önemli klinik ve teknik bilgileri senkronize etmek aynı zamanda paylaşmak zorundadır. Bu noktada hemşirelik dokümanları sağlı hizmetlerinin hayati bir unsurudur (34).

Hastanelerin son zamanlarda hastalar ve aileleri için daha iyi eğitim uygulamalarına yöneldiği gözlenmiştir. Geleneksel hasta eğitimi; hastalık süreçleri, ilaç tedavisi, tıbbi yönetim ve kişisel bakım kılavuzları hakkında yazılı materyallere dayanmaktaydı. Günümüzde yaygın olarak hasta bireyler televizyonlar, tabletler, hastalıklarını ve bakımlarını izleyebileceği, öğrenebileceği ve keşfedebileceği diğer gelişmiş elektronik cihazlar da dahil olmak üzere teknoloji yardımıyla eğitilmektedir $(35,38,39)$. Aynı zamanda günümüz sağlık anlayışı, bireyin kendi sağlı̆ğ ile ilgili sorumluluk almasını, hasta olmadan önce sağlıklı yaşamaya ve sağlığını korumaya özen göstermesini gerektirmektedir. $\mathrm{Bu}$ anlayış; bireylerin sağlık verilerini yanında taşıyabildiği, istediği zaman tüm sağlık verilerine ulaşılabildiği ve bunların her zaman kontrol altında tutulduğu, hastaları aktif kılan yaklaşımdır. $\mathrm{Bu}$ anlayış mobil sağlık uygulamalarının ön plana çıkmasına neden olmaktadır. Türkiye'nin de bu mobil uygulama pazarına dahil olarak sağlık bilişimi alanında kendi yazılım ve donanımlarını oluşturması, aplikasyon üreticilerinin ülkenin sağlı eğilimine göre, terminolojik olarak anlaş1lır mobil uygulamalar olarak tasarlaması gerektiği belirtilmektedir (40). Hasta bireylere verilen bakım hizmetinin yönetiminde kullanılacak olan teknolojinin başarılı bir şekilde hemşirelik uygulamalarına 
entegre edilmesi gerekmektedir. $\mathrm{Bu}$ bağlamda kullanılacak olan mobil uygulama yazılımının araştırmacı tarafından yapılmasının daha uygun olacağ1 düşünülmektedir. Böylece mobil sağl1k uygulamaların daha etkin bir şekilde sürdürülebilirliği sağlanacak ve güncellemeler yapılacaktır. Tasarımı yapılmakta olan mobil sağlık uygulaması ile hemodiyaliz hastalarında arteriyovenöz fistül bakımında güvenilir ve kullanışlı teknoloji temelli eğitim materyali oluşturulması planlanmaktadır. Ayrıca bu mobil uygulama ile hastanın kendine olan güveninin artması ve kendini güvende hissetmesi, hasta-sağlık personeli arasındaki iletişimi geliştirmesi, kullanım açısından bireyi özgür kılması, hasta bireylerin sağlık kuruluşuna gitmeden danışabilecekleri bir sistem hedeflenmektedir. Ayrica hasta bireylerin aktif bir şekilde kendi öz bakımlarına katılması, sorumluluk alması, hastanın evden takip ve bakımına olanak sağlanması gibi birçok açıdan olumlu katkısı olacağı düşünülmektedir. Bu mobil sağlık uygulaması ile hemodiyaliz hastalarında arteriyovenöz fistül bakımında bireylerin öz bakım konusunda bilinçlenmesi, becerilerinin artması ve oluşabilecek komplikasyonların erken tanılanması konusunda katk1 sağlayacağ1 düşünülmektedir. Uzun vadede oluşabilecek komplikasyonların engellenmesi ve etkili bir bakım ile maliyeti etkin bir çözüm oluşturması da hedeflenmektedir. Ayrıca makalenin, bu konu ile ilgili literatürde önemli bir açığı kapatması ve bilgi iletişim teknolojisinin hemşirelik bakım uygulamalarında bizzat hemşireler tarafindan entegre edilerek bir makale örneği teşkil etmesi, mesleğin
BİT kullanılarak bilimsel bilgi üretimine ve sağlık alanında Türkçe mobil uygulama açığına katkı sağlaması açısından önemli bir örnek teşkil edeceği düşünülmektedir.

\section{SONUÇ}

Bilim ve teknolojinin çok hızla geliştiği günümüzde hem özel hem de profesyonel iş yaşantımızda bu gelişmeleri takip etmek bir zorunluluk haline gelmiştir. Günlük yaşantımızın vazgeçilmezi haline gelen teknolojilerden akıllı cep telefonlarının ismine yakışır bir şekilde kullanılmas1 önem arz etmektedir. Bu bağlamda sağlik hizmeti sunduğumuz bireylere de bu doğrultuda etkili bir eğitim ve yaklaşım sergilemek düşüncesi ile yola çıkılmıştır. Makalede sunulan bilgiler doğrultusunda M-Sağlık uygulamalarının bireyleri öz bakım becerilerine teşvik etmek, komplikasyonları ve sağlık maliyetlerini azaltmak, bireyin refah seviyesini geliştirmek için tercih edilen bir yaklaşım olduğu görülmektedir. M-Sağlığın kronik durumları yönetmedeki yararını, hastalığa uyum ve kendi kendini izleme yeteneği gibi müdahalelerde etkili olduğu gösterilmiştir. Bu bağlamda mobil sağlığın hastalıkların bakımı ve yönetimi konusunda umut vaat ettiği görülmektedir. Arteriyovenöz fistül ve bakımı bireyin sürekli kendi kendini yönetmesi gereken diyaliz tedavisinin en zor yanları arasındadır. Hemşireler her zaman zorlukları birlikte aşmada hastalara en yakın sağlık profesyoneli olmuşlardır ve bu zorluğun teknolojinin yaşamı kolaylaştırıcı etkileri ile optimum seviyede tutulması hedeflenmektedir.

\section{Kaynaklar}

1. Digital 2019: Global Internet Use Accelerates. https://wearesocial.com/blog/2019/01/digital-2019-global-internet-useaccelerates (Erişim Tarihi: 30.12.2019)

2. Worldwide Quarterly Mobile Phone Tracker (IDC). (Worldwide üç aylık cep telefonu izleyici). http://www.idc.com/ getdoc.jsp?containerId=IDC_P8397 (Erişim Tarihi: 30.12.2019)

3. Yılmazel G, Çetinkaya F. Sağlık okuryazarlığının toplum sağlığı açısından. TAF Preventive Medicine Bulletin, 2016; 15(1): 69-74.

4. Ertek S. Endokrinolojide Tele-Sağlık ve Tele-Tıp Uygulamaları. Acıbadem Üniversitesi Sağlık Bilimleri Dergisi 2011; 2(3): 126-130.

5. Öney Doğanyiğit S. (2014). Sağlık Hizmetleri İletişiminde Mobil Sağlı: “Adımsayar” Uygulaması Örneği. Yayınlanmamış Yüksek Lisans Tezi, Galatasaray Üniversitesi. https://tez.yok.gov.tr/UlusalTezMerkezi/tezSorgu SonucYeni.jsp 
6. Mather C, Cummings E, Allen P. Nurses' Use of Mobile Devices to Access Information in Health Care Environments in Australia: A Survey of Undergraduate Students. JMIR Mhealth Uhealth 2014; 2(4): e56. doi:10.2196/mhealth.3467

7. Moorhead S, Hazlett D, Harrison L, Carroll J, Irwin A et al. A New Dimension of Health Care: Systematic Review of the Uses, Benefits, and Limitations of Social Media for Health Communication. J Med Internet Res 2013; 15(4): e85.

8. Rolls K, Hansen M, Jackson D, Elliott D. How Health Care Professionals Use Social Media to Create Virtual Communities: An Integrative Review. Journal of Medical Internet Research 2016; 18(6): e166.

9. Laranjo L, Arguel A, Neves A, Gallagher A, Kaplan R et al. The Influence of Social Networking Sites on Health Behavior Change: A Systematic Review and Meta-Analysis. J Am Med Inform Assoc 2014; 22(1): 243-56.

10. Bahia L, Araujo D, Schaan B, Dib S, Negrato C et al. The costs of type 2 diabetes mellitus outpatient care in the Brazilian public health system. Value Health 2011; 14(5): 137-40.

11. Alemdar H, Çınar Pakyüz S. Hemodiyaliz Hastalarında Öz Bakım Gücünün Yaşam Kalitesine Etkisinin Değerlendirilmesi. Nefroloji Hemşireliği Dergisi 2015; 10(2): 19-30.

12. Ovayolu N, Üriner Sistem Hastalıkları ve Hemşirelik Yönetimi. İçinde: N. Ovayolu, \& Ö. Ovayolu, Temel İç Hastalıkları Hemşireliği ve Farklı Boyutlarıyla Kronik Hastalıklar Kitabı, Adana, Nobel Tıp Kitabevi; 2016:373-378.

13. Yang MM, Zhao HH, Ding XQ, Zhu GH., Yang ZH et al. Self-Care Behavior of Hemodialysis Patients With Arteriovenous Fistula in China: A Multicenter, Cross-Sectional Study. Ther Apher Dial 2019; 23(2): 167-172.

14. Sungur G, Tekinsoy P, Ceyhan Ö, Taşçı S, Şahin S et al. Hemodiyaliz Hastalarının Evde Bakım Gereksinimleri. Nefroloji Hemşireliği Dergisi 2009; 6(1-2): 17-21.

15. Lourine Severo O, Dóris Firmino R, Nelma Caires Q. Life style, perceived control and quality of life: a study with the aged population of Patos de Minas-MG. Estud pesqui psicol 2012; 12(2): 416-430.

16. Kahn J, Yang J, Kahn J. 'Mobile' health needs and opportunities in developing countries. Health Aff (Millwood) 2010; 29(2): 252-8.

17. Accountability Commission for health of women and children. World Health Organization. https://www.who.int/ topics/millennium_development_goals/accountability_commission/en/(Erişim tarihi: 19.12.2019)

18. Vecchione, Anthony. Health-Monitoring Devices Market Outpaces Telehealth. InformationWeek. https://www.informationweek.com/mobile/health-monitoring-devices-market-outpaces-telehealth/d/d-id/1104636 (Erişim tarihi: 15.01.2020)

19. Krishna S, Austin Boren S, Balas E. Healthcare via cell phones: a systematic review. Telemed J E Health 2009; 15(3): 231-40.

20. Shemesh T, Barnoy S. Assessment of the Intention to Use Mobile Health Applications Using a Technology Acceptance Model in an Israeli Adult Population. Telemed J E Health 2020 doi:10.1089/tmj.2019.0144

21. Riley W, Rivera D, Atienza A, Nilsen W, Allison, S et al. Health behavior models in the age of mobile interventions: are our theories up to the task? Transl Behav Med 2011; 1(1): 53-71.

22. Dolan B. Timeline: The iPhone as medical tool. Mobihealthnews. https://www.mobihealthnews.com/2580/timeline-theiphone-as-medical-tool (Erişim tarihi: 19.12.2019)

23. Elliott T, Shih J, Dinakar C, Portnoy J, Fineman S. American College of Allergy, Asthma \& Immunology Position Paper on the Use of Telemedicine for Allergists. Ann Allergy Asthma Immunol 2017; 119(6): 512-517.

24. Burns M, Begale M, Duffecy J, Gergle D, Karr C et al. Harnessing context sensing to develop a mobile intervention for depression. J Med Internet Res 2011; 13(3): e55.

25. Bellin M, Dicianno B, Osteen P, Dosa N, Aparicio E et al, Family satisfaction, pain, and quality-of-life in emerging adults with spina bifida: a longitudinal analysis. Am J Phys Med Rehabil 2013; 92(8): 641-55.

26. Dicianno B, Lovelace J, Peele P, Fassinger C, Houck P et al. Effectiveness of a Wellness Program for Individuals With Spina Bifida and Spinal Cord Injury Within an Integrated Delivery System. Arch Phys Med Rehabil 2016; 97(11): 19691978.

27. Turner J, Larsen M, Tarassenko L, Neil A, Farmer A. Implementation of telehealth support for patients with type 2 diabetes using insulin treatment: an exploratory study. Inform Prim Care 2009; 17(1): 47-53.

28. Jongh T, Gurol-Urganci I, Vodopivec-Jamsek V, Car J, Atun R. Mobile phone messaging for facilitating self-management of long-term illnesses. Cochrane Database Syst Rev 2012; 12(12): CD007459. doi:10.1002/14651858.CD007459.pub2

29. Whitehead L, Seaton P. The Effectiveness of Self-Management Mobile Phone and Tablet Apps in Long-term Condition Management: A Systematic Review. J Med Internet Res 2016; 187(5): e97.

30. Akpolat T, Utaş C. Hemodiyaliz Hekimi El Kitabı. Kayseri: Türk Nefroloji Derneği Yayın Organı İkinci Baskı, Anodolu Yayıncılik; 2001. s. 5-11. 
31. Türkiye 2018 Yılı Ulusal Nefroloji, Diyaliz ve Transplantasyon Kayıt Sistemi Raporu. Ankara: T.C. Sağlık Bakanlığı ve Türk Nefroloji Derneği Ortak Raporu, 2019 http://www.nefroloji.org.tr/folders/file/REGISTRY_2018.pdf (Erişim tarihi: 12.01.2020)

32. Türk Nefroloji Derneği 2017 Yı1ı Türk Böbrek Kayıt Sistemi Raporu. http://www.nefroloji.org.tr/folders/file/TND2017-Kayit-Sistemi-Verileri.pdf (Erişim tarihi: 12.12.2019)

33. Durmaz Akyol A. Hemodiyaliz Hastalarında Yaşam Kalitesini Etkileyen Faktörlerin İncelenmesi. Nefroloji Hemşireliği Dergisi 2016; 11(1): 17-33.

34. Position Statement on Transforming Nursing Practice through Technology \& Informatics. Healthcare Information and Management Systems Society (HIMMS). https://www.himss.org/sites/hde/files/d7/HIMSSorg/handouts/ HIMSSNIPositionStatementMonographReport.pdf. (Erişim tarihi: 29.12.2019)

35. Cassano C. The Right Balance-Technology and Patient Care. Healthcare Information and Management Systems Society (HIMMS). https://www.himss.org/resources/right-balance-technology-and-patient-care (Erişim tarihi: 19.12.2019).

36. Darvish A, Salsali M. A Review On Information Technology Development And The Necessity Of Nursing Informatics Specialty. 4th International Technology, Education and Development Conference, 2010; s. 3320-3324).

37. Elkind E. Why information systems are helpful to nursing. Pa Nurse 2009; 64(1): 24-5.

38. Alligood M. Nursing theorists \& their work (8th) St. Louis: MO: Mosby. 2014: s: 240-258.

39. Shinners J, Graebe J. Continuing Education as a Core Component of Nursing Professional Development. J Contin Educ Nurs 2020; 51(1): 6-8.

40. Uğur, A. Bilişimin Türkçeleşmesi. https://saglikbilisimdernegi.org/tr/bilisimin-turkcelesmesi/ (Erişim tarihi: 01.03.2020) 